\title{
Benign familial chorea: an association with intellectual impairment
}

\author{
DANO A LELI, THOMAS W FURLOW JR, JANET C FALGOUT \\ From the Department of Neurology, University of Alabama in Birmingham, Birmingham, Alabama USA
}

SUMMARY Twenty-four members of a family with benign familial chorea underwent testing for evidence of intellectual impairment. Lower verbal intelligence was found in affected individuals compared to unaffected family members, as were deficits in verbal abstract concept formation. These results challenge the notion that benign familial chorea uniformly spares the intellect in all kindreds.

Benign familial chorea is a heritary disorder characterised by nonprogressive choreiform movements that appear in childhood and by the absence of dementia or mental retardation..$^{1-4}$ Genetic transmission of benign familial chorea follows the pattern of an autosomal dominant trait with incomplete penetrance ${ }^{5}$ though autosomal recessive transmission also has been reported. ${ }^{6}$

The preservation of mental faculties in individuals with benign familial chorea is a clinical hallmark distinguishing them from patients with Huntington's chorea. In cases of benign familial chorea where intellectual function has been formally assessed, scores often fall in the mildly retarded to low average range of intelligence, but typical indicators of organically based cognitive deterioration are not evident. ${ }^{1-4}$ When borderline mental retardation has been noted, it has been uniformly attributed to socioeconomic factors or variables not related to CNS dysfunction. ${ }^{1-4}$ In none of these cases, however, were attempts made to assess unaffected family members as a basis for comparison.

On the other hand, certain authors have described instances of educational difficulty and patterns of test results consistent with specific learning disabilities in patients with benign familial chorea. ${ }^{5}$ During clinical evaluation of a large kindred of

Presented in part at the International Neuropsychological Society, Pittsburgh, Feb. 1982.

Address for reprint requests: Dr Leli, Dept of Neurology, University of Alabama in Birmingham, Birmingham, Alabama 35294, USA.

Received 5 May 1983 and in final revised form 27 October 1983. Accepted 18 November 1983 benign familial chorea in Alabama, we also found that many of the affected children were described by school officials as "slow learners", "learning disabled", "handicapped", and "needing special education". Intellectual assessments of a small sample of affected and unaffected individuals tended to support the impression that intellectual impairment was associated with benign familial chorea in this kindred. The present investigation has pursued these preliminary findings through a cross-sectional study of most of the family. The specific aims of this study were (1) to determine if intellectual impairment is associated with benign familial chorea, and (2) if so, to determine the nature of this impairment.

\section{Methods}

A four-generation Caucasian pedigree of benign familial chorea was identified in and about Jefferson County, Alabama. The disease appeared as a mutation in a woman (the proposita) who transmitted it to four of her five daughters (fig). Affected family members were diagnosed on the basis of historical information and physical findings by a board-certified neurologist (TWF) independently of the intellectual assessment.

Affected members in the kindred manifested choreiform movements of the hands and feet while awake early in the first year of life. The frequency and amplitude of the movements gradually increased into early childhood and occasionally as late as adolescence, after which they remained stable or improved somewhat. Chorea was subtle in some family members and obvious in others. Psychomotor development of those with benign familial chorea was commonly delayed. HLA typing in 20 individuals was normal. No other systematic laboratory studies were performed. In two individuals, haemogram, urine analysis, blood chemistries, ASO titre, ceruloplasmin, 

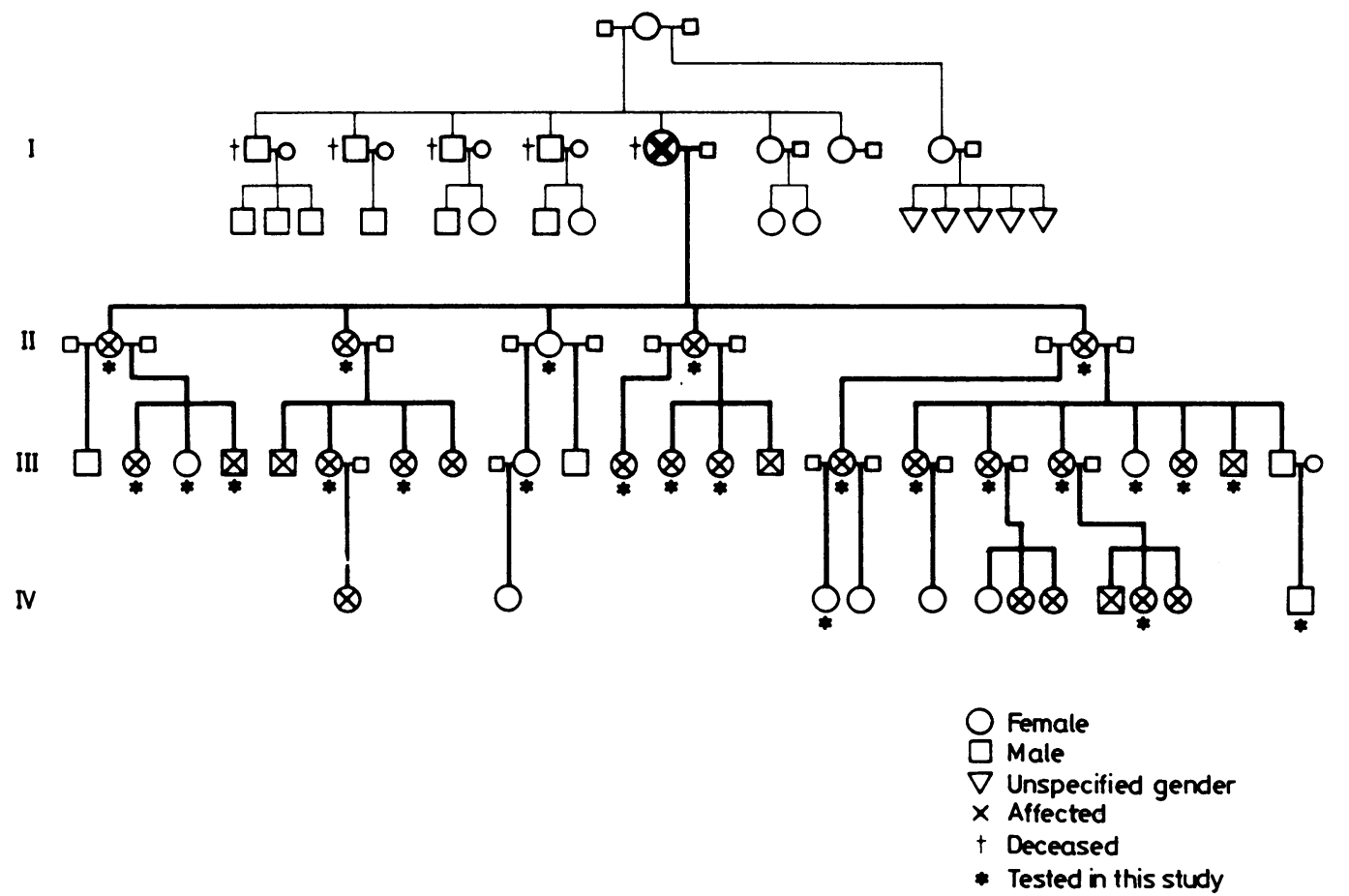

Fig 1 The pedigree of large family with benign familial chorea $(B F C)$. The disease appeared as a mutation in a woman who transmitted it to four of five daughters. The affected generations are numbered 1 to 4 on the right. Although benign familial chorea follows a dominant mode of genetic transmission, this pedigree does not permit a conclusion as to whether the disease is autosomal or sex-linked in the absence of transmission from father to son. Family members who participated in this study are marked by asterisks.

computed tomography of the head, and EEG were negative. One individual was taking thorazine ( $30 \mathrm{mg}$ per day) over a four month period prior to the intellectual assessment while three other individuals were taking oxazepam (10-50 mg per day) for one to 3 years prior to the intellectual assessment. To our knowledge none of the other family members with benign familial chorea were taking psychoactive medications.

Eighteen family members with benign familial chorea ( 16 females, two males) and six unaffected individuals (five females, one male) within the extended family were available for intellectual evaluation. The affected sample included 14 right-handed, two left-handed, and two ambidextrous individuals, while the unaffected sample included five right-handed, and one left-handed individual.

Intellectual assessments were conducted by two neuropsychologists (DAL and JCF) with consistent efforts to encourage optimal levels of performance in each individual, since the presence of choreiform movements often precluded a "blind" assessment. One of the following intelligence tests was administered depending on the subject's age: the Wechsler Preschool and Primary Scale of Intellig- ence (WPPSI) $(n=2)$, the Wechsler Intelligence Scale for Children-Revised (WISC-R) $(n=7)$, and the Wechsler Adult Intelligence Scale (WAIS) $(n=15)$. The two subjects who were administered the WPPSI were included in the group comparisons because of high correlations between the WPPSI and WISC-R IQ scores' and the continuity of seven of the 10 WPPSI subtests with those from the WISC-R.

The independent variable in this study was group membership while the following demographic and psychometric variables served as dependent measurements: age, educational level, sex, handedness, Full Scale IQ, Verbal IQ, Performance IQ, and the 11 subtest scale scores for the WAIS, WISC-R, and WPPSI, where appropriate. Picture Arrangement, Object Assembly, Digit Span, and Coding scores were not available for the two subjects who were administered the WPPSI. Age equivalent scaled scores were used for the WAIS subtests since WISC-R and WPPSI subtest scores are computed according to agestratified norms. The WAIS IQ scores were computed in the traditional fashion. The table depicts the age, educational, and psychometric data for the BFC-affected and 
Table 1 Demographic and IQ Data in Benign Familial Chorea (BFC)

\begin{tabular}{|c|c|c|c|c|c|c|c|c|}
\hline & \multicolumn{4}{|c|}{ BFC Affected Family Members } & \multicolumn{4}{|c|}{ Unaffected Family Members } \\
\hline & $N$ & Mean & $S D$ & Range & $N$ & Mean & $S D$ & Range \\
\hline $\begin{array}{l}\text { Age } \\
\text { Education } \\
\text { Verbal IQ } \\
\text { Performance IQ } \\
\text { Full scale IQ } \\
\text { Information } \\
\text { Comprehension } \\
\text { Arithmetic } \\
\text { Similarities } \\
\text { Digit Span* } \\
\text { Vocabulary } \\
\text { Coding* } \\
\text { Picture completion } \\
\text { Block design } \\
\text { Picture arrangement* } \\
\text { Object assembly** }\end{array}$ & $\begin{array}{l}18 \\
18 \\
18 \\
18 \\
18 \\
18 \\
18 \\
18 \\
18 \\
17 \\
18 \\
17 \\
18 \\
18 \\
17 \\
17\end{array}$ & $\begin{array}{r}21 \cdot 28 \\
7 \cdot 06 \\
77 \cdot 00 \\
83 \cdot 11 \\
78 \cdot 33 \\
5 \cdot 33 \\
6 \cdot 61 \\
6 \cdot 06 \\
7 \cdot 11 \\
7 \cdot 65 \\
4 \cdot 50 \\
6 \cdot 00 \\
8 \cdot 06 \\
6 \cdot 78 \\
8 \cdot 06 \\
7 \cdot 82\end{array}$ & $\begin{array}{r}11 \cdot 43 \\
2 \cdot 82 \\
11 \cdot 69 \\
14 \cdot 80 \\
13.07 \\
1.71 \\
2 \cdot 52 \\
2.13 \\
3.05 \\
1.54 \\
2 \cdot 87 \\
1.80 \\
2 \cdot 36 \\
3.00 \\
3.51 \\
3.03\end{array}$ & $\begin{array}{l}6-45 \\
1-12 \\
56-96 \\
57-103 \\
56-98 \\
2-8 \\
3-12 \\
3-10 \\
0-10 \\
6-11 \\
0-10 \\
2-9 \\
3-12 \\
2-12 \\
3-16 \\
2-12\end{array}$ & $\begin{array}{l}6 \\
6 \\
6 \\
6 \\
6 \\
6 \\
6 \\
6 \\
6 \\
5 \\
6 \\
5 \\
5 \\
6 \\
6 \\
5 \\
5\end{array}$ & $\begin{array}{r}17 \cdot 83 \\
6 \cdot 17 \\
91 \cdot 50 \\
86 \cdot 67 \\
88 \cdot 50 \\
7 \cdot 17 \\
7 \cdot 00 \\
7 \cdot 50 \\
10 \cdot 33 \\
8 \cdot 80 \\
7 \cdot 33 \\
7 \cdot 40 \\
6 \cdot 83 \\
7 \cdot 17 \\
8 \cdot 60 \\
8 \cdot 40\end{array}$ & $\begin{array}{r}12 \cdot 35 \\
3 \cdot 97 \\
18 \cdot 15 \\
9 \cdot 11 \\
14 \cdot 57 \\
3 \cdot 19 \\
2 \cdot 28 \\
2 \cdot 26 \\
4 \cdot 13 \\
3 \cdot 63 \\
3 \cdot 72 \\
2 \cdot 07 \\
1 \cdot 94 \\
1 \cdot 72 \\
4 \cdot 16 \\
2 \cdot 19\end{array}$ & $\begin{array}{c}5-40 \\
1-12 \\
70-120 \\
76-100 \\
71-112 \\
4-13 \\
5-10 \\
6-12 \\
5-15 \\
4-12 \\
4-14 \\
4-9 \\
3-8 \\
5-9 \\
4-15 \\
6-10\end{array}$ \\
\hline
\end{tabular}

*Scores from these subtests were unavailable for the two individuals who were administered the WPPSI.

unaffected family members.

For the dependent variables of age, educational level, and the 14 psychometric variables, the two samples were compared via a series of one-way analyses of variance using the least squares method for unequal sample sizes. ${ }^{8}$ Chi-square analyses were used to determine if the samples differed in sexual composition of handedness.

\section{Results}

The two samples did not differ as a function of age $(F(1,22)=0.537, \mathrm{p}<0.54)$, education $(F(1,22)=$ $0.37, \mathrm{p}<0.55)$, sex $\left(\chi^{2}(1)=0.127, \mathrm{p}<0.28\right)$, or handedness $\left(\chi^{2}(2)=0 \cdot 800, p<0.33\right)$. Inspection of the table indicates that the unaffected family members had higher mean intelligence test scores on 13 of the 14 variables with Picture Completion being the one exception. The two samples differed significantly on Verbal IQ $(F(1,22)=5 \cdot 24, \mathrm{p}<$ $0.03)$ and Similarities $(F(1,22)=4.23, \mathrm{p}<0.05)$ scores. Mean differences between the samples on Information $(F(1,22)=3 \cdot 30, p<0.08)$, and Vocabulary $(F(1,22)=3 \cdot 79, \mathrm{p}<0.06)$ subtest scores also approached statistical significance.

\section{Discussion}

The IQ data depicted in the table and the results from the analyses of variance indicate that impaired verbal intellectual abilities are associated with the presence of benign familial chorea, independent of sex and education, in a kindred having a common socioeconomic background. The affected family members' verbal concept formation skills (Similarities subtest) were the most clearly affected abilities, with a tendency for their word knowledge
(Vocabulary subtest) and general fund of information (Information subtest) also to be affected. The nature of the global and specific intellectual deficits suggests that, relative to the nonaffected individuals, affected individuals from this kindred should perform more poorly on academic tasks requiring verbal mediation and abstract reasoning. These results are consistent with a case report in the literature ${ }^{5}$ and reports from the local school system concerning the presence of learning disabilities in several of the affected subjects in this kindred.

To assess the possibility that these group differences were due to drug related suppression of test performance, the Verbal IQ and Similarities scores from the four individuals taking medication were examined. Two of the three individuals taking oxazepam and the individual taking thorazine had Verbal IQ scores ranging from 84 to 93 and Similarities scores of 10,10 , and 9 respectively. These scores are well above the mean scores of the group with benign familial chorea for these variables (see table). The remaining individual taking oxazepam had a Verbal IQ of 72 and a Similarities score of 2 which are both very close to the group mean scores for the affected individuals depicted in the table. These data appear to rule out the suppression of test performance due to medication and if anything suggest that task performance may have been enhanced.

In conclusion, the results of this investigation suggest that intellectual impairment is associated with benign familial chorea in the present kindred. Further studies are obviously needed to demonstrate whether this relationship is universal or not. These results challenge the notion that benign familial chorea uniformly spares the intellect in all kindreds. 


\section{References}

' Pincus JH, Chutorian A. Familial benign chorea with intention tremor: a clinical entity? $J$ Pediat 1967;70:724-9.

${ }^{2}$ Haerer AF, Currier RD, Jackson JF. Hereditary nonprogressive chorea of early onset. New Eng J Med 1967;276:1220-4.

${ }^{3}$ Sadjadpour K, Amato RS. Hereditary non-progressive chorea of early onset: a new entity? Adv Neurol 1973;1:79-91.

${ }^{4}$ Sleigh G, Lindenbaum H. Benign (non-paroxysmal) familial chorea. Arch Dis Child 1981;56:616-21.

5 Chun RWM, Daly RF, Mansheim BJ, et al. Benign familial chorea with onset in childhood. JAMA 1973;225: 1603-7.

- Nutting PA, Cole BR, Schimke RN. Benign, recessively inherited choreo-athetosis of early onset. J Med Genet 1969;6:408-10.

${ }^{7}$ Wechsler D. Wechsler Intelligence Scale for ChildrenRevised (Manual). New York, NY: The Psychological Corporation, 1974.

${ }^{8}$ Helwig JT, Council KA, eds. SAS User's Guide. Cary, NC, SAS Institute, Inc., 1979. 